\title{
CURRÍCULO E PRÁTICA PEDAGÓGICA DA EDUCAÇÃO FÍSICA
}

\author{
Paulo Roberto Veloso Ventura *
}

RESUMO

O artigo em questão trata de temas que hoje integram as discussões sobre Educação Física, como currículo e prática pedagógica, numa dimensão mais política e mais pedagógica. Trata também da própria identidade deste campo do conhecimento, além de outros temas que o rodeiam: educação, ensino, professor, escola. Projeta ainda, futuros embates que certamente terão influência nas estruturas da Educação Física.

\begin{abstract}
A
o pensar em currículo e prática pedagógica da Educação Física, estabeleço num primeiro momento algumas discussões de temáticas estreitamente relacionadas com as consideradas centrais. Assim, inicio minha abordagem com o tema Educação. Conforme Snyders, ${ }^{1}$ "para fazermos Educação, temos que segurar as duas pontas da corrente: numa, revolucionar o ensino, o que implica uma revolução social, e na outra, dar aulas amanhã cedo".

Segundo Libâneo (1998, p. 71), "o processo educativo é um fenômeno social, enraizado nas contradições, nas lutas sociais, de modo que é nos embates da práxis social que vai se configurando o ideal de formação humana".
\end{abstract}

Para o autor,

A educação nunca pode ser a mesma em todas as épocas e lugares devido ao seu caráter socialmente determinado. As normas sociais, os valores, os modelos de vida, de trabalho e de relações entre as pessoas correspondem a modelos socialmente dominantes encarnados pelas classes que detêm o poder econômico e político (...). A prática educativa intencional compreende, assim, todo fato, influência, ação, processo,

\footnotetext{
* Professor graduado e especialista em Educação Física e mestre em Educação; vinculado à Eseffego - unidade de Goiânia da Universidade Estadual de Goiás; sócio-pesquisador do CBCE; membro do Fórum Goiano em Defesa da Escola Pública; membro do Fórum das Licenciaturas da UEG.
} 
que intervém na configuração da existência humana, individual ou grupal, em suas relações mútuas, num determinado contexto histórico-social (Libâneo, 1998, p. 72).

Acompanhando o pensamento do autor, percebe-se que a educação é uma atividade intencional, impulsionada conforme fins que se estabelecem dentro do quadro de interesses das classes sociais, que identificam o caráter crítico-social da educação.

O campo educativo é bastante vasto; assim, a educação ocorre em diversas dimensões, como na família, no trabalho, na rua, na escola, nos meios de comunicação, na política e, para espanto de muitos, nas prisões. Com isso, cumpre distinguir diferentes manifestações e modalidades de prática educativa, tais como a educação informal, não-formal e formal.

A educação informal corresponderia a ações e influências exercidas pelo meio, pelo ambiente sociocultural. Ela se desenvolve por meio das relações dos indivíduos e grupos com seu ambiente humano, social, ecológico, físico e cultural, das quais resultam conhecimentos, experiências e práticas, mas que não estão ligadas especificamente a uma instituição nem são intencionais e organizadas. A educação não-formal seria a realizada em segmentos educativos fora dos marcos da instituição escolar, mas com certo grau de sistematização e estruturação. A educação formal compreenderia instâncias de formação, escolares ou não, com objetivos educativos explícitos e uma ação intencional institucionalizada, estruturada, sistemática.

Há uma interpenetração constante entre essas três modalidades, que, embora distintas, não podem ser consideradas isoladamente. Se existem diferentes práticas educativas, em muitos lugares e sob variadas modalidades, há, por conseqüência, várias práticas pedagógicas: a familiar, a sindical, a dos meios de comunicação etc., e também, é claro, a prática pedagógica escolar.

Então, o que é a escola, vista como a instituição responsável pela educação formal e que faz uso de uma prática pedagógica escolar?

Segundo Pistrak (apud Ventura, 2000, p. 36), 
A escola refletiu sempre o seu tempo e não podia deixar de refletilo; sempre esteve a serviço das necessidades de um regime social determinado e se não fosse capaz disso, teria sido eliminada como um corpo estranho e inútil.

Este pensamento mostra quão difícil é trabalhar com educação, especialmente se transferimos esse desafio para um país capitalista, considerado em desenvolvimento, como o nosso, onde as pirâmides sobre a apropriação do capital e sobre as possibilidades de continuidade nos estudos estão presentes na demarcação/separação das classes sociais. Para Carmen Soares (1996, p. 6),

Talvez a escola pudesse ser um lugar onde se vai para aprender coisas que não se sabe, ou que se sabe apenas na superfície. (...) A escola então estaria tratando de saberes mais elaborados ou, conforme Snyders, rompendo com a cultura primeira, ampliando o horizonte do aluno para coisas, lugares e saberes que ele não atingiria sem ela. (...) Esta escola como lugar de conhecer, estaria colocando, para o aluno, o que há de grandioso na ciência, ou seja, o homem diante da dúvida, diante de um processo que se constrói pelos erros e pela negação... por rupturas e continuidades e, sobretudo, por interesses humanos.

Segundo Soares (1996, p. 7), quando Snyders se refere à escola, ele fala da alegria da descoberta, da alegria de se aproximar do que é mais elaborado, do que é difícil, daquilo que não seria possível sem o professor e sem a escola. Afirma assim, para a escola, os saberes científicos, técnicos e estéticos, e a escola como algo diferente da vida corrente e, exatamente por isto, desafiador.

Mas, então, dentro da escola como se aprende os diversos saberes? Para Paulo Freire (1997. p. 25),

não existe docência sem discência; é preciso que desde o começo do processo, vá ficando cada vez mais claro que, embora diferentes entre si, quem forma se forma e re-forma ao formar e quem é formado forma-se e forma ao ser formado. É neste sentido que ensinar não é transferir conhecimentos, conteúdos, nem formar é ação pela qual um sujeito criador dá forma, estilo ou alma a um corpo indeciso e acomodado. Não há docência sem discência, as duas se explicam e seus sujeitos, apesar das diferenças que os conotam, não se reduzem à 
condição de objeto um do outro. Quem ensina aprende ao ensinar e quem aprende ensina ao aprender. (...) ensinar não é transferir conhecimento, mas criar as possibilidades para a sua produção ou a sua construção.

Esta afirmação confirma o ensinar como uma via de mão dupla. Mas quem na escola é tido como ensinante, apesar do que disse Freire? Tem sido colocado que quem ensina é o professor. O sistema faz da escola o mais poderoso aparelho ideólogico do Estado - na concepção de Althusser,$-{ }^{2}$ porque esta instituição opera com um singular instrumento que é o currículo, cujo grande operador é o professor, elemento da maior competência para sedimentar as ideologias dominantes e que faz o papel funcional de (re)transmiti-las.

$\mathrm{O}$ professor não pode e não deve ser apenas o (re)passador de conhecimentos produzidos com objetivos e intencionalidades dos quais ele não participa ou com os quais não concorda. Para tanto, ele deve participar da construção, elaboração ou contextualização dos saberes tidos, da seleção dos conteúdos a ser apreendidos por seus alunos. Quando o professor é capaz de detectar as intencionalidades de inculcação dominante e recusa-se a trabalhar dentro do ordenamento oficial, o desenho que lhe apresentam como opção traz um emaranhado tão eclético e confuso que suas chances de erro são consideráveis. Castellani Filho (1991, p. 17) pinta este cenário:

Era uma vez... Um grande 'quebra-cabeça'. As peças estavam todas embrulhadas aleatoriamente em cima de um enorme tabuleiro. Dispor as peças ordenadamente, compondo o quadro, era o objetivo maior a ser alcançado (...) A duração do jogo? A vida inteira. Seu significado? A busca da própria compreensão do mundo em que vivemos.

Ao nos propormos falar do professor, questionamos: o que pode o professor? De acordo com Paulo Freire (1997, p. 84), sendo professor,

tenho o direito de ter raiva, de manifestá-la, de tê-la como motivação para minha briga tal qual tenho o direito de amar, de expressar meu amor ao mundo, de tê-lo como motivação de minha briga por- 
que, histórico, vivo a História como tempo de possibilidade e não de determinação.

Para além disto, o professor não deve ser objeto, mas, sim, sujeito de seu projeto histórico e do processo histórico no qual está envolvido. Conforme Freire (1991, p. 86), "ninguém pode estar no mundo, com o mundo e com os outros de forma neutra (...). Há perguntas a serem feitas insistentemente por todos nós e que nos fazem ver a impossibilidade de "estudar por estudar".

As perguntas a que Freire se refere estariam em meu entendimento no patamar de: "Em favor de que estudo? Em favor de quem estudo? Contra que estudo? Contra quem estudo?". Então, se o próprio Freire diz que "quem ensina aprende ao ensinar", posso considerar que a referência "estudar" utilizada pelo autor se aplica não só ao aluno, mas também ao professor. Nesta direção, podemos alterar as perguntas anteriores: "Em favor de que ensino? Em favor de quem ensino? Contra que ensino? Contra quem ensino?". Assim, precisamos detectar quais questões precisam ser abordadas na prática pedagógica que desenvolvemos com nossos alunos e, por conta disto, que conhecimento precisamos dominar.

Disso tudo, e considerando que o professor não pode ser neutro, entendo que ele precisa tomar partido, estar a favor de ou contra alguma coisa ou alguém, não omitindo, em sua mediação, nenhuma das "verdades", tendo em vista a perspectiva de não ser detentor da verdade maior, pois esta se radica em ambos os lados; no conflito, cada qual acredita na sua concepção. No projeto de transformação, vejo que o professor precisa dominar conhecimentos suficientes para mostrar com competência em que sociedade deseja se inserir.

Alinhavando então um dos temas centrais, questionamos: o que é Educação Física? Para o Projeto Curricular do Curso de Licenciatura Plena em Educação Física da Eseffego (1998),

a Educação Física é um campo de conhecimento específico da Cultura Corporal, universal, organizado socialmente e tematizado nas suas formas naturais, artificiais e adaptadas, através de atividades como o jogo, a dança, o esporte, a luta e a ginástica, tendo relevância na sociedade, por ser componente do processo educacional do lazer, 
da saúde, da comunicação e do mundo do trabalho, manifestando em sua práxis, as dimensões técnica, científica, política e cultural.

Esta concepção tem base na obra do Coletivo de Autores (1992) e toma a cultura corporal como objeto de estudo da Educação Física, advindo do paradigma da teoria crítico-superadora, sistematizada a partir de concepções críticas da educação. Esta concepção se apropria, problematiza e pedagogiza temas específicos da cultura corporal, como o jogo, a ginástica, a dança, a luta e o esporte, desenvolvidos em quaisquer dos campos de trabalho da Educação Física.

Percebo a prática da Educação Física como uma prática pedagógica. E como surge uma determinada prática pedagógica?

Ela surge de necessidades sociais concretas. Sendo a Educação Física uma prática pedagógica, podemos afirmar que ela surge de necessidades sociais concretas que, identificadas em diferentes momentos históricos, dão origem a diferentes entendimentos do que dela conhecemos. (Coletivo de Autores, 1992, p. 50)

Constato também que a Educação Física, sendo uma prática pedagógica surgida de necessidades sociais, se estabelece como uma prática social. Veiga (1992, p. 16) assim associa esta relação:

Entendo a prática pedagógica como uma prática social orientada por objetivos, finalidades e conhecimentos, e inserida no contexto da prática social. A prática pedagógica é uma dimensão da prática social que pressupõe a relação teoria-prática, e é essencialmente nosso dever, como educadores, a busca de condições necessárias à sua realização.

Sendo social, a prática pedagógica da Educação Física deve estabelecer uma concepção de conhecimento no viés de uma relação entre sujeito e objeto, uma relação dialética que garanta a unidade entre teoria e prática, implicando ainda uma relação entre sujeitos. No entanto, as pesquisas realizadas em minha dissertação de mestrado (Ventura, 2000) mostram que essa prática pedagógica parece estar num patamar em que a relação do professor dentro do processo escolar "não apresenta nenhuma reciprocidade entre su- 
jeitos", ficando à mercê de inconsciente reprodução do saber, que ratifica as condições dominantes de uma escola mantida pelas políticas ideológicas do neoliberalismo; ou seja, a relação que prevalece é a de um sujeito sobre outros sujeitos e parece estar mais para as questões práticas e objetivas, o que inibe também a relação dialética.

Para modificar o quadro da atual prática pedagógica da Educação Física, torna-se elementar que os professores coloquem suas ações a serviço de um projeto de educação voltado para as questões sociais, com vertente emancipatória, pois um contingente maior destes profissionais detém uma prática pedagógica previamente determinada pelas sociedades civil e política, o que nos leva a presumir que estejam alienados em formulações prontas e acabadas. Estas formulações mantêm a escola e seus atores debaixo da vertente intelectual do poder e da cultura dominantes. Se a escola é o local onde se disseminam estes valores, o instrumento utilizado no seu interior para tal disseminação é o currículo.

O modelo de escola que temos hoje surgiu após a Revolução Francesa, no século XVIII, para atender à classe emergente da época, a burguesia. Desde então, esta permanece hegemônica e determina uma conotação funcional para a escola, realizando, através do processo de exclusão, o papel de reprodução do sistema capitalista dominante.

Este sistema, subsidiado pelas políticas neoliberais, forma hoje o que muitos autores da sociologia crítica chamam de "nova direita". Esta se irmana com a prática de um "Estado mínimo", porém muito forte, e que se impõe na educação através da privatização e da comercialização de nossas escolas, com os mecanismos de adoção de livros didáticos, programas de vídeo e TV fechada, entre outras estratégias. Assim, o "conhecimento oficial" é aquele que a classe hegemônica/burguesa quer impor à classe dominada através das escolas, usando como instrumento o currículo. Em algumas dessas escolas, onde se pode contar com professores com uma visão crítica, acontecem discussões e conflitos. Para Paulo Freire, citado em Apple (1997),

construir caminhos políticos e pedagógicos em direção a uma educação crítica e democrática requer que lutemos contra a hegemonia 
das elites intelectuais que têm tradicionalmente definido o que é chamado de conhecimento oficial...

Mas, o que é o currículo? Poderia dizer que é o instrumento utilizado no interior da escola para instalar o conhecimento oficial, elaborado pelas elites intelectuais dominantes. No senso comum, mesmo entre atores da escola, o currículo é visto como sinônimo de grade curricular, o que empobrece e reduz seu entendimento. Conforme Moreira e Silva (1995, p. 28),

o currículo não é o veículo de algo transmitido e passivamente absorvido, mas o terreno em que ativamente se criará e produzirá cultura. O currículo é, assim, um terreno de produção e de política cultural, no qual os materiais existentes funcionam como matériaprima de criação, recriação e, sobretudo, de contestação e transgressão.

Nestas condições, o papel do currículo está bem definido, como campo de discussões ideológicas onde ocorrem conflitos nas áreas política, social e cultural. Assim, ao entender o currículo como um elemento político de grande relevância, que instrumentaliza a escola para exercer o papel funcional de reproduzir o sistema que a mantém, posso entendê-lo também como meio de conduzir investidas contra-hegemônicas, oportunizando, dentro desta estrutura de desigualdades sociais, leituras críticas aos atores da escola, excluídos do processo elitizante, e proporcionando-lhes os conhecimentos necessários que os levem ao direito/dever de desfrutar de sua cidadania.

Etimologicamente, currículo vem do latim curriculum, que significa corrida, caminhada, percurso. Por analogia, o Coletivo de Autores (1992, p. 27) faz uma primeira aproximação conceitual:

O currículo escolar representaria o percurso do homem no seu processo de apreensão do conhecimento científico selecionado pela escola: seu projeto de escolarização. (...) o objeto do currículo é a reflexão do aluno. A escola não desenvolve o conhecimento científico. Ela se apropria dele, dando-lhe um tratamento metodológico de modo a facilitar a sua apreensão pelo aluno. O que a escola desenvol- 
ve é a reflexão do aluno sobre esse conhecimento, sua capacidade intelectual. A amplitude e a qualidade dessa reflexão é determinada pela natureza do conhecimento selecionado e apresentado pela escola, bem como pela perspectiva epistemológica, filosófica e ideológica adotada.

Historicamente, o desenvolvimento curricular no processo educacional brasileiro tem sua gênese num caráter elitista de ensino. Não através de uma proposta sistemática de currículo, mas por tradições curriculares com uma base filosófica montada num ecletismo similar ao positivismo de autores como Herbart, Pestalozzi e os padres jesuítas. Neles destacam-se três tendências: ênfase em disciplinas literárias e acadêmicas, enciclopedismo e divisão entre trabalho manual e intelectual. Esta fase permaneceu até a $1^{\text {a }}$ Guerra Mundial, quando se iniciaram as reformas educacionais promovidas pelos "pioneiros da educação", que inseriram as idéias progressivistas da Escola Nova.

Essa proposta promoveu uma importante ruptura com a escola tradicional, dando ênfase à natureza social do processo escolar

por sua preocupação em renovar o currículo, por sua tentativa de modernizar métodos e estratégias de ensino e de avaliação e, ainda, por sua insistência na democratização da sala de aula e da relação professor-aluno. (Moreira, 1995, p. 93)

As estruturas dessa nova teoria são montadas com base nos autores americanos Dewey e Kilpatrick e nos europeus Claparède, Decroly e Montessori.

Os conflitos sociais e políticos na década de 1920 e a crise econômica de 1929, em consequiência da quebra da Bolsa de Nova York, levaram o Brasil à Revolução de 1930, que conduziu Getúlio Vargas ao governo por 15 anos. Até 1937, manteve-se um Estado populista, cujo processo de industrialização recebeu aval do governo e provocou conflitos com os trabalhadores; com a ideologia nacionalista conviveu um período liberal, cujas agitações foram inevitáveis, culminando com um processo autoritário chamado Estado Novo. Este diminuiu a influência progressivista da Escola Nova, 
priorizando o ensino profissionalizante e a postura conservadora. Com a volta do ensino enciclopédico, instala-se também a importância dos especialistas. Em 1951, novamente voltamos a um Estado democrático, com Vargas eleito pelo povo para a Presidência da República.

Após o suicídio de Vargas, em 1954, Juscelino Kubitschek elege-se presidente em 1956, ano da instalação do Programa de Assistência Brasileira-Americana à Educação Elementar (PABAEE) - programa que visava a um intercâmbio entre Brasil e Estados Unidos. Nossos docentes deslocavam-se até as universidades dos Estados Unidos para estudos de pós-graduação, e os americanos enviavam técnicos para efetuar treinamentos com nossos professores e especialistas. Registre-se também a influência do Instituto Nacional de Estudos e Pesquisas Educacionais (Inep), criado em 1938 com a missão de tratar as questões educacionais relacionadas com os trabalhos do Ministério da Educação e Saúde, o qual, dentre suas ações, também trazia técnicos americanos para treinar nossos profissionais ligados à educação.

Assim, as questões curriculares no Brasil tiveram influências, em sua origem, daquilo que chamamos de "transferência educacional", especialmente dos EUA, entendida como "o movimento de idéias, de modelos institucionais e de práticas de um país para outro" (Moreira, 1995, p.18).

Em 1962, a disciplina Currículos e Programas foi introduzida nos cursos de Pedagogia, como disciplina eletiva. Em 1969, ela passa a ser obrigatória para os estudantes que buscavam formar-se supervisores escolares, fato que marcaria sua inserção definitiva na grade de disciplinas das Faculdades de Educação. Em 1972, surge o primeiro curso de mestrado em currículo, na Universidade de Santa Maria (RS). Nos cursos de Educação Física, não disponho de maiores dados sobre a inserção de disciplina específica para estudos sobre currículo. Em Goiás, na Eseffego/UEG, isto ocorre apenas a partir da implantação do currículo de 1994.

Segundo Moreira, a transferência educacional para o Brasil aconteceu na perspectiva de três enfoques: no contexto internacional (condições internacionais), ou seja, as influências exteriores na educação brasileira; no "contexto sociocultural, econômico e político 
brasileiros" (condições societárias), ou seja, dentro das atividades curriculares práticas e teóricas não isoladas das lutas econômicas, políticas e ideológicas da sociedade mais ampla; e no "contexto institucional, cultural e ideativo" (condições processuais), esclarecendo o papel das instituições, das políticas educacionais, das reformas, dos debates, encontros, conflitos, das alianças etc.

A tradição curricular americana transferida para o Brasil foi analisada e reelaborada por Domingues (professor do Programa de Mestrado da Faculdade de Educação da UFG), em 1985, com base em paradigmas estabelecidos nos estudos de James MacDonald: paradigma circular consensual - com base no progressismo da Escola Nova, tem interesse em compreensão e em consenso e se apóia em autores como Dewey e Kilpatrick; paradigma técnico linear com bases tecnicistas, tem interesse no controle técnico e apoio em Tyller e Taba; paradigma dinâmico dialógico - com base em teorias críticas, a partir de Habermas, demonstra interesse em emancipação e se fundamenta em Apple e Giroux.

Assim, as influências curriculares vêm de classes dominantes de países dominantes, abraçadas pela classe dominante daqui, a classe burguesa. Apple tem uma posição interessante a respeito da dominação burguesa:

Os poderosos não são assim tão poderosos. As políticas do Conhecimento Oficial são o resultado de acordos e compromissos (...). Os compromissos ocorrem em diferentes níveis (...). Estes, com certeza, não são compromissos que se dão entre iguais. Aqueles que dominam quase sempre têm mais poder para definir o que se considera como uma necessidade ou um problema e qual deveria ser uma resposta apropriada a ele. Mas estes compromissos não são estáveis. Eles quase sempre deixam ou criam espaços para uma ação mais democrática (...). Haverá sempre brechas para a atividade contra-hegemônica. (Apple, 1997, p. 24-25)

Mas, concretamente, o que compõe o currículo? Quais são seus elementos? Conforme minha compreensão, divido os componentes curriculares em dois pontos:

1) O primeiro trata dos processos históricos: da instituição; do campo do conhecimento; do próprio currículo da instituição (no caso de revisão curricular); 
2) O segundo trata da caracterização do curso, das concepções e do eixo epistemológico:

a) Concepção do entendimento sobre o campo do conhecimento em questão;

b) Perfil de pessoa e profissional que se quer formar (atenção ao aluno-cidadão que estará sob os cuidados da instituição, durante a formação proposta);

c) Finalidade do curso (justificativa e relevância pedagógicosocial do curso);

d) Objetivo(s) do curso (geral e/ou específicos);

e) Avaliação da aprendizagem (ligada ao objetivo, formando com este um par dialético) - deve ser processual, não ter fim em si mesma;

f) Conteúdos - direcionados pelas ementas e explicitados pelos programas;

g) Metodologia - formará par dialético com os conteúdos, pela estreita relação entre si;

h) Grade curricular - deverá ser elaborada após constituídos os eixos curriculares e não servir de pilar para estes, como normalmente acontece;

i) Os eixos de um currículo se fincam em questões como a relação interdisciplinar, a relação teoria-prática e a indissociabilidade ensino-pesquisa-extensão;

j) Bibliografia (que dará pistas sobre a tendência político-pedagógica do currículo).

Para fechar este texto que se propôs falar de currículo e prática pedagógica da Educação Física, não poderia deixar de citar que na atualidade existem três grandes questões presentes nas discussões que envolvem os currículos das escolas de Educação Física no Brasil: a primeira trata das diretrizes curriculares para os cursos de Educação Física, que apontam, entre outras coisas, o fim do bacharelado $^{2}$ e a criação de áreas de aprofundamento no final dos estudos; a segunda se refere à questão do provão, que determinará, junto com a $1^{a}$ questão, o rumo dos currículos das escolas de Educação Física; a terceira se refere ao $\operatorname{Confef}^{3}$ e à lei que regulamenta a atividade do profissional de Educação Física. Para falar dessas 
questões, haverá necessidade de organizar um novo texto, que entendo necessário e oportuno, pois vejo novos tempos de ebulição na Educação Física brasileira. O currículo será, então, fator de influência e será influenciado pelas discussões, pelos conflitos e pelas sistematizações, na busca da identidade deste campo do conhecimento científico.

Para tanto, teremos que nos dispor às discussões, não aceitando que apenas uma elite, especialmente uma elite dominante, possa estabelecer "as verdades" da Educação Física. Busco em Gramsci uma citação forte o bastante para nos levar às reflexões necessárias, especialmente para que não fiquemos indiferentes ao processo histórico:

A indiferença opera poderosamente na história... O que acontece, não acontece tanto porque alguns querem que aconteça, mas porque a massa dos homens abdica da sua vontade, deixa fazer, deixa agrupar nós que depois só a espada poderá cortar, deixa promulgar as leis que depois só a revolta fará anular, deixa exercer o poder a homens que depois só um motim poderá derrubar. (Gramsci, apud Taffarel, 1997, p. 870)

\section{ABSTRACT}

This article deals with subjects currently integrated in the discussion about Physical Education, such as the curriculum and the pedagogical practice in a more political and pedagogical dimension. It also deals with the identity of this field of knowledge, beside other subjects related to it, such as education, teaching, teacher and school. In addition, it foresees future shocks which will certainly have influence upon the structure of Physical Education.

\section{NOTAS}

${ }^{1}$ Esta citação foi feita pela Professora Doutora Carmen Lúcia Soares, da cadeira de Prática de Ensino na FE/Unicamp, em palestra proferida na Eseffego, em 1996.

${ }^{2}$ No meu modo de ver, trata-se de uma proposta falaciosa, porque na verdade irá sedimentar os bacharelados, de forma disfarçada.

${ }^{3}$ Conselho Federal de Educação Física, criado pela Lei n. ${ }^{\circ}$ 9.696/ 98, sancionada em $1 .^{\circ}$ de setembro de 1998. 


\section{REFERÊNCIAS}

APPLE, Michael A. Conhecimento oficial. Petrópolis: Vozes, 1997.

CASTELLANJ FILHO, Lino. Educação Física no Brasil: a história que não se conta. 3. ed. Campinas: Papirus, 1991.

COLETIVO DE AUTORES. Metodologia do ensino de Educação Física. São Paulo: Cortez, 1992.

FREIRE, Paulo. Pedagogia da autonomia. Rio de Janeiro: Paz e Terra, 1997.

LIBÂNEO, José Carlos. Perspectivas de uma pedagogia emancipadora face às transformações do mundo contemporâneo. Pensar a Prática. Goiânia: FEF/UFG, v. 1, n. 1, 1998.

MOREIRA, Antonio F. B. Currículos e programas no Brasil. 2. ed. Campinas: Papirus, 1995.

MOREIRA, Antonio F. B.; SILVA, Tomaz Tadeu. (Orgs.). Currículo: questões atuais. Campinas: Papirus, 1997.

Currículo, cultura e sociedade. São Paulo: Cortez, 1995.

SOARES, Carmen Lucia. Educação Física escolar: conhecimento e especificidade. Revista Paulista de Educação Física, São Paulo, supl. 2, 1996.

TAFFAREL, Celi N. Z. O processo do trabalho pedagógico e o trato com o conhecimento no curso de Educação Física. In: BRZEZINSKI, Iria. (Org.). Formação de professores: um desafio. Goiânia: UCG, 1996.

UNIVERSIDADE ESTADUAL DE GOIÁS. Projeto curricular do curso de Educação Física da ESEFFEGO. Goiânia, 1999.

VEIGA, Ilma Passos. A prática pedagógica doprofessor de Didática. Campinas: Papirus, 1992.

VENTURA, Paulo Roberto V. A prática pedagógica da Educação Física em escolas públicas de Goiânia. 2000. Dissertação (Mestrado) - Universidade de Brasília. 